\title{
Helicobacter pylori cagA+ Is Associated with Milder Duodenal Histological Changes in Chilean Celiac Patients
}

\author{
Yalda Lucero ${ }^{1,2,3 *}$, Amaya Oyarzún ${ }^{4}$, Miguel O'Ryan ${ }^{3,5}$, Rodrigo Quera $^{6}$, Nelly Espinosa ${ }^{7}$, \\ Romina Valenzuela ${ }^{2}$, Daniela Simian ${ }^{6}$, Elisa Alcalde ${ }^{1}$, Claudio Arce ${ }^{1}$, Mauricio J. Farfán ${ }^{1,2}$, \\ Alejandra F. Vergara ${ }^{1}$, Iván Gajardo ${ }^{2}$, Jocelyn Mendez ${ }^{1}$, Jorge Carrasco ${ }^{1}$, \\ Germán Errázuriz ${ }^{6}$, Mónica Gonzalez $^{8}$, Juan C. Ossa ${ }^{1,2}$, Eduardo Maiza ${ }^{9}$, \\ Francisco Perez-Bravo ${ }^{10}$, Magdalena Castro ${ }^{5}$ and Magdalena Araya ${ }^{3}$ \\ ${ }^{1}$ Hospital Dr. Luis Calvo Mackenna, Santiago, Chile, ${ }^{2}$ Department of Pediatrics and Pediatric Surgery, Faculty of Medicine, \\ University of Chile, Santiago, Chile, ${ }^{3}$ Microbiology and Micology Program, Faculty of Medicine, University of Chile, Santiago, \\ Chile, ${ }^{4}$ Laboratory of Immunegenetics, Institute of Nutrition and Food Technology, University of Chile, Santiago, Chile, \\ ${ }^{5}$ Millenium Institute of Immunology and Immunotherapy, Faculty of Medicine, University of Chile, Santiago, Chile, \\ ${ }^{6}$ Department of Gastroenterology, Clínica Las Condes, Santiago, Chile, ${ }^{7}$ Hospital Militar, Santiago, Chile, ${ }^{8}$ Hospital Dr. \\ Roberto del Río, Santiago, Chile, ${ }^{9}$ Clínica Las Lilas, Santiago, Chile, ${ }^{10}$ Nutrition Program, Faculty of Medicine, University of \\ Chile, Santiago, Chile
}

\section{HIGHLIGHTS}

OPEN ACCESS

Edited by:

D. Scott Merrell,

Uniformed Services University,

United States

Reviewed by:

Fabio Bagnoli,

GlaxoSmithKline, Italy

Richard Louis Ferrero,

Hudson Institute of Medical Research,

Australia

${ }^{*}$ Correspondence:

Yalda Lucero

ylucero@med.uchile.cl

Received: 31 May 2017 Accepted: 08 August 2017 Published: 23 August 2017

Citation:

Lucero Y, Oyarzún A, O'Ryan M, Quera R, Espinosa N, Valenzuela R, Simian D, Alcalde E, Arce C, Farfán MJ, Vergara AF, Gajardo I, Mendez J, Carrasco J, Errázuriz G,

Gonzalez M, Ossa JC, Maiza E, Perez-Bravo F, Castro M and Araya M (2017) Helicobacter pylori cagA+ Is

Associated with Milder Duodenal Histological Changes in Chilean Celiac Patients.

Front. Cell. Infect. Microbiol. 7:376. doi: 10.3389/fcimb.2017.00376
- What is already known about this subject?

- Celiac disease (CD) has a high clinical and histological diversity and the mechanisms underlying this phenomenon remain elusive.

- H. pylori is a bacterium that chronically infect gastric and duodenal mucosa activating both a Th1/Th17 and T-reg pathways.

- The role of $H$. pylori (and the effect of their virulence factors) in CD have not yet completely elucidated.

- What are the new findings?

- cagA $+H$. pylori strains are associated to milder histological damage in infected CD patients.

- In active-CD patients the presence of cagA+ H. pylori is associated to an increase in T-reg markers, contrasting with a downregulation in cagA+ infected potential-CD individuals.

- How might it impact on clinical practice in the foreseeable future?

- The identification of microbiological factors that could modulate inflammation and clinical expression of $C D$ may be used in the future as preventive strategies or as supplementary treatment in patients that cannot achieve complete remission, contributing to the better care of these patients.

Background: Mechanisms underlying the high clinical and histological diversity of celiac disease (CD) remain elusive. Helicobacter pylori (Hp) chronically infects gastric and duodenal mucosa and has been associated with protection against some immune-mediated conditions, but its role (specifically of cagA+ strains) in CD is unclear.

Objective: To assess the relationship between gastric $\mathrm{Hp}$ infection (cagA+ strains) and duodenal histological damage in patients with CD. 
Design: Case-control study including patients with active-CD, potential-CD and nonceliac individuals. Clinical presentation, HLA genotype, Hp/cagA gene detection in gastric mucosa, duodenal histology, Foxp3 positive cells and TGF- $\beta$ expression in duodenal lamina propria were analyzed.

Results: We recruited 116 patients, 29 active-CD, 37 potential-CD, and 50 non-CD controls. Hp detection was similar in the three groups ( $30-40 \%)$, but cagA+ strains were more common in infected potential-CD than in active-CD (10/11 vs. 4/10; $p=$ $0.020)$ and non-CD (10/20; $p=0.025)$. Among active-CD patients, Foxp3 positivity was significantly higher in subjects with cagA $+\mathrm{Hp}+$ compared to cagA- $\mathrm{Hp}+(p<0.01)$ and $\mathrm{Hp}-(p<0.01)$. In cagA $+\mathrm{Hp}+$ individuals, Foxp3 positivity was also higher comparing active- to potential-CD $(p<0.01)$. TGF- $\beta$ expression in duodenum was similar in active$\mathrm{CD}$ with cagA $+\mathrm{Hp}+$ compared to $\mathrm{Hp}$ - and was significantly downregulated in $\mathrm{cagA}+$ potential-CD subjects compared to other groups.

Conclusion: $\mathrm{Hp}$ infection rates were similar among individuals with/without $\mathrm{CD}$, but infection with cagA + strains was associated with milder histological damage in celiac patients infected by $\mathrm{Hp}$, and in active-CD cases with higher expression of T-reg markers. Results suggest that infection by cagA + Hp may be protective for CD progression, or conversely, that these strains are prone to colonize intestinal mucosa with less severe damage.

Keywords: celiac disease, potential celiac disease, Helicobacter pylori, cagA gene, duodenal atrophy

\section{INTRODUCTION}

Celiac disease (CD) is an immune-mediated systemic disorder triggered by ingested gluten and related prolamines in genetically susceptible individuals (Husby et al., 2012; Green et al., 2015). $\mathrm{CD}$ has progressively increased in prevalence and is associated with significant morbidity, impacting quality of life and health care costs (Biagetti et al., 2015; Burden et al., 2015; Catassi et al., 2015). Overall prevalence is nearly $1 \%$, ranging from 0.3 to $5 \%$ in different regions (Catassi et al., 2015; Green et al., 2015). In Chile, a National Health Survey performed in 2009 assessed a representative sample of individuals older than 15 years of age using anti-transglutaminase (tTG) antibodies detection and estimated a prevalence of $0.8 \%$ (Minsal Chile, 2010). Initially considered a gluten dependent enteropathy, $\mathrm{CD}$ is currently recognized as a systemic autoimmune disease with clinical manifestations ranging from asymptomatic to malabsorptive chronic diarrhea associated with severe malnutrition (Husby et al., 2012; Agardh et al., 2015; Green et al., 2015; Schøsler et al., 2016). Likewise, the intensity of inflammation and damage of the intestinal mucosa in untreated patients varies widely, from the absence of any detectable lesions to total mucosal atrophy (Donaldson et al., 2008; Husby et al., 2012). Mechanisms underlying this wide clinical and histological spectrum remain elusive.

The intestinal microbiota is currently under intense evaluation as a potentially relevant pathogenic factor in CD. Differential microbiota patterns in duodenal biopsies and stool samples have been described for CD patients as compared to healthy controls (Collado et al., 2008, 2009; Di Cagno et al.,
2011; Cenit et al., 2015). Helicobacter pylori (H. pylori), a Gramnegative, spiral bacterium capable of infecting human gastric mucosa, has also been isolated from the duodenum (Csendes et al., 1995; Kim et al., 2004; Nagasawa et al., 2009). There is evidence that $H$. pylori is associated with an increased regulatory $\mathrm{T}$ cell (T-reg) response in blood and gastric mucosa, mainly in children, and specifically with higher number of Foxp3+ T cells and higher expression of Foxp3 and TGF- $\beta$ mRNA/protein among other markers (Lundgren et al., 2005; Gil et al., 2014; Yang et al., 2014). In particular, CagA, a pleomorphic virulence factor of $\mathrm{H}$. pylori, involved in oncogenesis and epithelial barrier disfunction, has also been involved in T-reg pathway activation (Kido et al., 2011) (reviewed in Stein et al., 2013). Meta-analysis presented in recent systematic reviews suggest a protective role of H. pylori against atopy, an immune mediated disorder (Lionetti, 2014; Taye et al., 2015), and some studies have proposed a modulator role in $\mathrm{CD}$. Lebwohl et al. reported a strong inverse association between $H$. pylori presence in gastric mucosa and CD in a large cross-sectional study (Lebwohl et al., 2013). However, these findings have not been reproduced elsewhere (Jozefczuk et al., 2015; Simondi et al., 2015). Although, Simondi et al. did not find a difference in the prevalence of $H$. pylori between celiac and non-celiac individuals, they described an association of the presence of this bacterium in the gastric mucosa of celiac patients with milder duodenal lesions, suggesting $H$. pylori plays an immune regulator role (Simondi et al., 2015). Konturek et al. described lower seroprevalence of anti-cagA antibodies in celiac patients compared to healthy controls, suggesting a possible protective role of $H$. pylori harboring specific virulence factors (Konturek et al., 2000). 
We aimed to determine, using a case-control design, whether $H$. pylori gastric infection, specifically with cagA+ strains, is associated with reduced rates of duodenal atrophy in celiac patients. Our secondary aimwas to compare duodenal expression of representative T-reg markers among CD individuals with and without infection by $c a g A+H$. pylori and different histological severity. Our hypothesis was that infection with cagA+H. pylori would be more common among individuals with milder forms of $\mathrm{CD}$ and associated with an increase in expression of T-reg markers.

\section{METHODS}

\section{Study Design}

In a multicenter, prospective study performed in six hospitals in Santiago, Chile, subjects $1-50$ years of age evaluated by their treating gastroenterologists for symptoms suggestive of CD according to clinical judgment, were invited to participate in this study. Individuals older than 50 years of age were excluded in order to reduce the possibility of recruiting patients with gastric cancer. After informed consent (and assent when appropriate) subjects were tested for celiac serology (anti-tTG) and HLA typing. When anti-tTG was positive, patient was submitted to upper gastrointestinal endoscopy (UGE) in order to obtain gastric and duodenal biopsies. Age-matched non-CD patients undergoing UGE for chronic abdominal pain or chronic diarrhea were recruited in parallel and also subject to $\mathrm{CD}$ serology, gastric, and duodenal biopsies.

All patients answered a survey including questions related to family history, demographics, and gastrointestinal symptoms lasting at least 1 month during the previous year. Exclusion criteria were active upper gastrointestinal bleeding, therapeutic endoscopy, use of antimicrobials or proton pump inhibitors during the previous 4 weeks, confirmed allergic enteropathy, coagulopathy, cancer, immune-suppression or inflammatory bowel disease.

\section{Ethics}

This study was carried out in accordance with the recommendations of the Declaration of Helsinki. The protocol was approved by the IRBs of Faculty of Medicine, Universidad de Chile and the six participating centers (Hospital Dr. Luis Calvo Mackenna, Hospital Dr. Roberto del Río, Hospital Militar, Clínica Las Condes, Clínica Las Lilas, Institute of Nutrition, and Food Technology). Written informed consent was obtained from all subjects $>18$ years of age. In children, written informed consent was obtained on behalf of them from their Parents/Legal Guardians and in those $>8$ years of age, written informed assent was also obtained.

\section{Procedures \\ Diagnosis of CD CD serology}

Total IgA and IgA anti-tTG were determined in serum by a commercial ELISA kit $\left(\right.$ Alpco $^{\circledR}$, USA and AESKU ${ }^{\circledR}$, Germany, respectively) following the manufacturer's instructions. When total serum IgA was below the cut off value for the patient's age and IgA anti-tTG was negative $(<12 \mathrm{UI} / \mathrm{ml})$ or in a weak positive range (12-18 UI/ml), IgA/IgG anti-tTG was measured using the Celicheck kit (AESKU ${ }^{\circledR}$, Germany). CD serology was considered positive when IgA anti-tTG was $>18 \mathrm{UI} / \mathrm{ml}$ in patients with normal levels of total IgA and/or IgA/IgG anti-tTG was $>24$ $\mathrm{UI} / \mathrm{ml}$.

\section{Duodenal histopathology}

At least four duodenal biopsy specimens, including a bulb sample were paraffin embedded; 4 micron sections were stained with hematoxylin-eosin and graded by an expert pathologist, blind to anti-tTG and H. pylori status, following the Marsh-Oberhuber classification (Marsh, 1989).

\section{HLA-DQ genetic studies}

HLA haplotype determination was performed to fully characterize the $\mathrm{CD}$ population and specifically to strength the diagnostic evidence of potential CD cases. HLA haplotypes were determined in blood using the commercial PCR kit DQ-CD Typing plus (BioDiagene ${ }^{\circledR}$, Italy) as previously described (Araya et al., 2015). Results were expressed according to three categories: DQ2/DQ2 or DQ2/DQ8; DQ8-DQ8 or DQ8-DQ7; or non-identifiable with the kit used.

\section{Histology, H. pylori, and cagA Detection in Gastric Mucosa}

Rapid urease testing was performed on antral and corporal biopsies obtained during endoscopy, using the Pronto-Dry ${ }^{\circledR}$ test (MIC France, France). Results were considered positive when color change from yellow to pink was evident, according to the manufacturer's instructions. Formalin-fixed paraffin-embedded antral and corporal biopsies were stained with hematoxylineosin and Warthin Starry for routine histological evaluation and $H$. pylori detection, respectively. Gastric histological damage was categorized according to the Sydney system (Stolte and Meining, 2001). Total DNA from gastric biopsies was extracted with the QIAamp RNA/DNA minikit (Qiagen Sciences, Germany) and quantified by spectrophtometry. To verify $H$. pylori DNA presence in gastric samples, amplification was performed by real time PCR using the commercial kit, Sacace $^{\mathrm{TM}}$ H. pylori Real-TM (Sacace Biotechnologies Srl, Italy). DNA template quality was confirmed in negative samples by actin gene amplification (Genesig kit ${ }^{\circledR}$, Primer Design, United Kingdom). The cagA gene was assessed in $H$. pylori positive individuals by real-time PCR of gastric tissue, as previously described (Sepúlveda et al., 2012). In brief, we used the Fast EvaGreen dye qPCR master mix (Biotium, Hayward, CA) with $4 \mu \mathrm{l}$ of total purified DNA from each sample and the following primer pair: forward: 5ATAATGCTAAATTAGACAACTTGAGCGA-3' and reverse: 5'-TTAGAATAATCAACAAACATCACGCCAT-3' (Sepúlveda et al., 2012). Negative (water) and positive (ATCC 26695 reference strain) controls were used in each assay for $H$. pylori and cagA detection. 


\section{Classification of CD and $\boldsymbol{H}$. pylori Infection Status}

Based on the presence of anti-tTG antibodies and the MarshOberhuber score, patients were classified in three groups: activeCD (positive anti-tTG antibodies and duodenal atrophy with a Marsh score of 3), potential-CD (positive anti-tTG antibodies and a Marsh score of $0-1$, indicating absence of duodenal villi atrophy) and non-CD patients (negative anti-tTG and the absence of duodenal atrophy). CD patients with a Marsh score of 2 (crypt hyperplasia with no villous atrophy) were excluded in order to avoid possible ambiguity in the disease severity criteria.

A subject was considered infected by $H$. pylori when the rapid urease test, Warthin Starry staining and H. pylori real-time PCR were all positive in gastric samples.

\section{Evaluation of T-reg Markers in Duodenal Samples}

We assessed the quantity of regulatory T-cells in duodenal mucosa of patients with and without cagA+H. pylori by measuring the number of Foxp3+ stained cells in lamina propria by immunohistochemistry. Sections of paraffin embedded duodenal biopsies from six randomly selected patients per group (or all those available for patient groups with $<6$ individuals) were incubated in Dako Autostainer ${ }^{\mathrm{TM}}$ with anti-human Foxp3 (1:50, Santa Cruz), following the manufacturer's instructions. The Envision ${ }^{\mathrm{TM}}$ system (Dako) was used to visualize staining of specimens counterstained with hematoxylin eosin. For each patient we calculated the mean number of stained cells in lamina propria per 10 high power fields for three different areas of the duodenal biopsies.

For duodenal TGF- $\beta 1$ measurements, we extracted total protein and RNA from mucosal samples preserved in RNA later ${ }^{\mathrm{TM}}$ using the AllPrep DNA/RNA/protein Mini $\mathrm{Kit}^{\mathrm{TM}}$ (Qiagen, Germany) following manufacturer instructions. Total RNA was reverse-transcribed by using AffinityScript ${ }^{\mathrm{TM}}$ qPCR cDNA kit (Stratagene). Synthesized cDNA was used to amplify TGF- $\beta 1$ and actin genes in duplicate using TaqMan ${ }^{\circledR}$ Gene Expression Assays (Applied Biosystems ${ }^{\mathrm{TM}}$, USA). TGF- $\beta 1$ expression levels were normalized to actin by subtracting the change in cycle threshold value $(\Delta \mathrm{Ct})$. Relative expression for specific patient groups was calculated as the ratio of their mean $\Delta \mathrm{Ct}$ divided by $\Delta \mathrm{Ct}$ of active-CD patients negative for $H$. pylori $(\Delta \Delta \mathrm{Ct})$.

TGF- $\beta 1$ protein concentrations from duodenal biopsies were determined by Luminex, according to manufacturer's instructions and normalized by $\mu \mathrm{g}$ of total protein measured by spectrophotometry.

\section{Statistical Analysis}

Categorical variables were compared between groups using the Chi-squared or Fisher's exact test; continuous variables were compared using the Mann-Whitney $U$ test. The Odds ratio of the association between severity of duodenal atrophy and the presence of cagA $+H$. pylori strains was calculated. A $p \leq 0.05$ was considered statistically significant. For sample size calculations, we considered an expected $H$. pylori prevalence of $40 \%$ based on previous reports on the young Chilean population (Porras et al., 2013; O'Ryan et al., 2015) and an overall frequency of cagA+ strains of $40-80 \%$ (Harris et al., 2003; O'Ryan et al., 2015). We hypothesized a 20\% detection rate of cagA+ strains in active-CD, $50 \%$ in non-CD and $80 \%$ in potential-CD patients. Twenty five cases per group would provide $80 \%$ power with a type-I error of 0.05 for a two-sided analysis.

\section{RESULTS}

\section{Patients}

A total of 226 individuals were screened between January 2013 and July 2015, of which 116 fulfilled the inclusion criteria, provided complete data and underwent analysis; 66 were CD patients (29 with active-CD and 37 with potential-CD) and 50 were non-CD patients (Figure 1).

$\mathrm{CD}$ and non-CD groups were comparable by age, gender and most clinical symptoms, with the exception of abdominal pain and recent weight loss, which were significantly more frequent in non-CD patients (Table $\mathbf{1}$ ).

Age distribution, the presence of other autoimmune conditions and a family history of CD were similar between potential- and active-CD patients (Table 2). A trend toward higher frequency of DQ2/DQ2 and DQ2/DQ8 haplotypes, the presence of abdominal distension and steatorrhea was observed in the active- $\mathrm{CD}$ group compared to potential-CD individuals. Female gender was more frequent, anti-tTG titers were higher and the rate of constipation was significantly lower in active-CD compared with potential-CD patients (Table 2).

\section{H. pylori and cagA Gene Detection in Gastric Mucosa}

The frequency of $H$. pylori detection in gastric mucosa did not differ between non-CD (20/50, 40\%), potential-CD (11/37, 30\%) and active-CD patients (10/29, 34\%) (Tables 1, 3). cagA gene detection in gastric mucosa of individuals infected with $H$. pylori was similar when comparing overall $\mathrm{CD}$ and non-CD patients (Table 1). However, in CD patients infected by $H$. pylori, cagA detection was significantly more common among individuals with potential (Marsh 0-1) compared to active-CD (Marsh 3) ( $p=0.02$; OR 15.0, 95\% CI: 1.3-167.7) (Table 3). This association with cagA+ strains was also significant when comparing $H$. pylori infected individuals with potential-CD and non-CD group $(p=$ 0.02; OR 10.0, 95\%CI 1.1-93.4).

In order to characterize the effect of $H$. pylori infection at the gastric level in our study population we compared histology results according to infection status. Overall histological gastritis was more common in non-CD subjects infected with $H$. pylori compared to non-infected patients $(p=0.003$; OR 7.6, 95\%CI 1.7-38.2); however there was only a trend toward increased gastritis in $H$. pylori positive individuals in the potential-CD $(p$ $=0.069)$ and active-CD groups $(p=0.091)$ (Table 4). There was no association between histological gastritis and $\operatorname{cag} A+$ strains (Table 4). We identified only three cases of atrophic gastritis (all in $H$. pylori negative individuals) and two cases of intestinal metaplasia (one in an H. pylori negative and one in an $H$. pylori positive subject) (Table 4). 


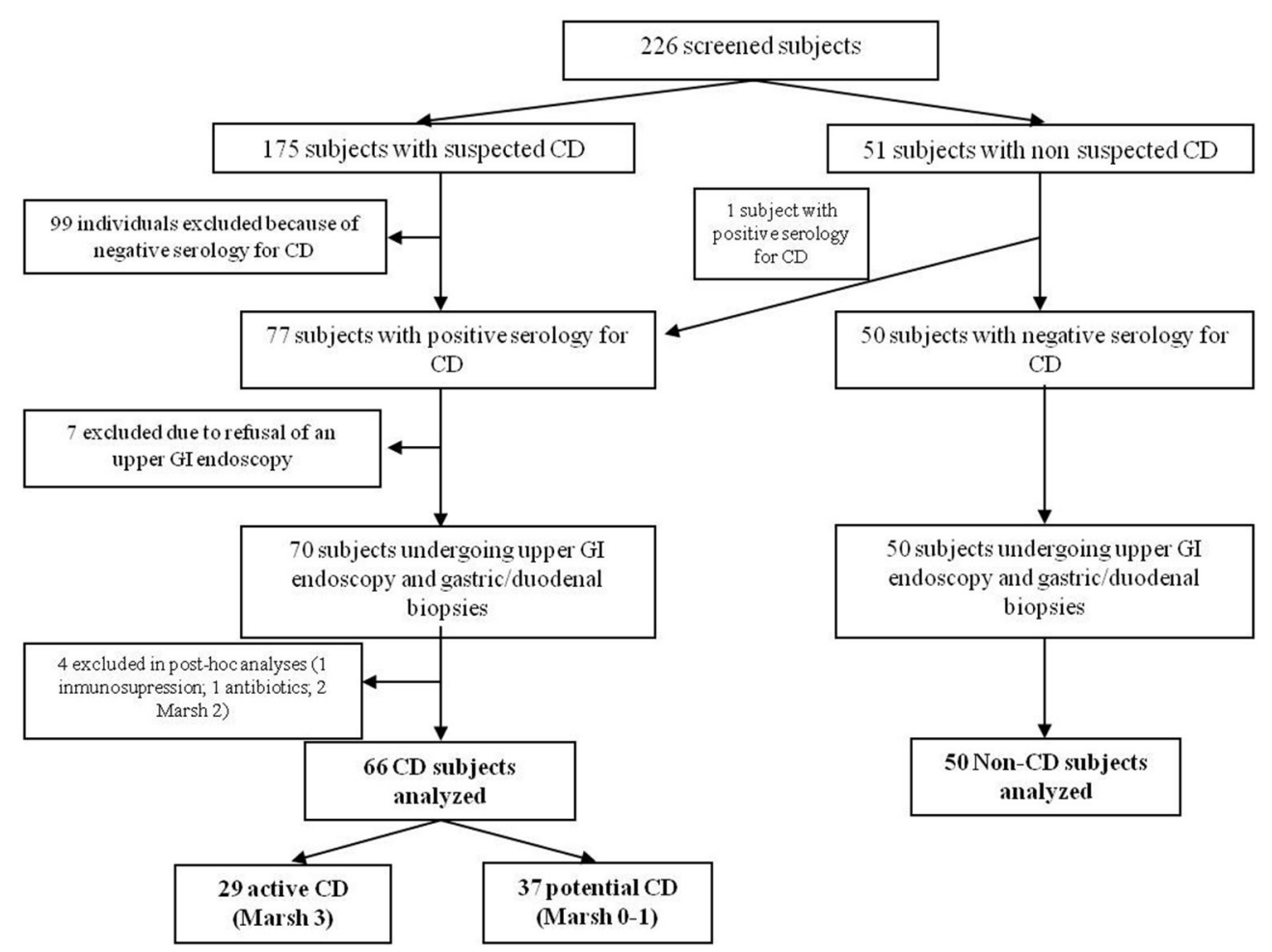

FIGURE 1 | Study flow chart.

TABLE 1 | Host characteristics, H. pylori and cagA detection in gastric mucosa of $66 \mathrm{CD}$ patients compared to 50 non-CD individuals.

\begin{tabular}{|c|c|c|c|c|}
\hline Characteristic & & CD patients $n=66$ & Non-CD patients $n=50$ & $p$-value \\
\hline Female, $n(\%)$ & & $40(61)$ & $32(64)$ & 0.35 \\
\hline & Bloating, n (\%) & $26(39)$ & $26(52)$ & 0.09 \\
\hline & Diarrhea, n (\%) & $22(33)$ & $20(40)$ & 0.23 \\
\hline & Constipation, n (\%) & $19(29)$ & $11(22)$ & 0.21 \\
\hline & Underweight, n (\%) & $8(12)$ & $11(22)$ & 0.08 \\
\hline & Vomits, n (\%) & $6(9)$ & $6(12)$ & 0.31 \\
\hline & Steatorrhea, n (\%) & $5(8)$ & $5(10)$ & 0.44 \\
\hline H. pylori positive, n (\%) & & $21(32)$ & $20(40)$ & 0.18 \\
\hline cagA infected individuals & & $14(21)$ & $10(20)$ & 0.44 \\
\hline
\end{tabular}

Bold values indicate significant difference $(p<0.05)$.

\section{Foxp3 Positive Cell Count and TGF- $\beta 1$ Expression in Duodenal Biopsies According to $H$. pylori and cagA Status}

Considering the association between cagA $+H$. pylori strains and milder histological damage in CD subjects, we assessed levels of selected T-reg markers in order to explore if this pathway could be involved in the halting of disease progression. Overall the median number of Foxp 3 positive cells in lamina propria was significantly higher in patients with active- compared to potential-CD (Figure 2). In the group of potential-CD subjects there was no difference between $H$. pylori infected and noninfected (Figure 2). In patients with active-CD infected with H. pylori cagA+ the number of Foxp3 positive cells was significantly higher compared to all the other active-CD groups as well as to potential-CD subjects infected by cagA $+H$. pylori $(p$ $<0.05$; Figure 2). 
TABLE 2 | Demographic, clinical, serological, and HLA profile of potential- and active-CD patients.

\begin{tabular}{|c|c|c|c|c|}
\hline & & Potential-CD $n=37$ & Active-CD $n=29$ & $p$-value \\
\hline Median age, years (IQR) & & $12(5-21)$ & $13(7-33)$ & 0.61 \\
\hline Female, n (\%) & & $18(49)$ & $22(76)$ & 0.01 \\
\hline Family history of CD, n (\%) & & $11(30)$ & $7(24)$ & 0.31 \\
\hline Median anti-transglutaminase levels, UI/ml (IQ range) & & $26.1(18.1-51.4)$ & $191.4(65.4-332.7)$ & $<0.0001$ \\
\hline & Non-identified & $2(5)$ & 0 & \\
\hline \multirow[t]{4}{*}{ Clinical presentation, n (\%) } & Diarrhea & $11(30)$ & $13(45)$ & 0.15 \\
\hline & Steatorrhea & $1(3)$ & $5(17)$ & 0.05 \\
\hline & Constipation & $14(38)$ & $5(17)$ & 0.03 \\
\hline & Abdominal distension & $13(35)$ & $15(52)$ & 0.09 \\
\hline
\end{tabular}

Bold values indicate significant difference $(p<0.05)$.

TABLE 3 | H. pylori and cagA detection in patients with potential- and active-CD.

\begin{tabular}{|c|c|c|c|c|}
\hline & $\begin{array}{c}\text { Potential-CD } \\
n=37\end{array}$ & $\begin{array}{c}\text { Active-CD } \\
n=29\end{array}$ & $p$-value & OR (95\% Cl) \\
\hline $\begin{array}{l}\text { H. pylori positive, } \\
\mathrm{n}(\%)^{\star}\end{array}$ & $11(30)$ & $10(34)$ & 0.34 & $\begin{array}{c}0.80 \\
(0.28-2.28)\end{array}$ \\
\hline $\begin{array}{l}\text { cagA positive, } \\
\mathrm{n}(\%)\end{array}$ & $10(27)$ & $4(14)$ & 0.15 & $\begin{array}{c}2.31 \\
(0.64-8.33)\end{array}$ \\
\hline $\begin{array}{l}\text { cagA positive/ } \\
\text { H. pylori positive, } \\
(\%)^{\star *}\end{array}$ & 10/11 (91) & $4 / 10(40)$ & 0.02 & $\begin{array}{c}15.0 \\
(1.34-167.65)\end{array}$ \\
\hline
\end{tabular}

"A subject was considered positive for $\mathrm{H}$. pylori when rapid urease test, Warthin Starry staining and real time PCR in gastric mucosa were all positive.

${ }^{* *}$ comparison of cagA detection rate in patients infected by $H$. pylori.

Bold values indicate significant difference $(p<0.05)$.

TGF- $\beta 1$ protein concentration in duodenal biopsies showed a tendency to be higher in active-CD compared to potential CD overall $(p=0.19)$. Individuals infected by cag+ $H$. pylori strains did have lower TGF- $\beta 1$ levels than non-infected individuals, that was statistically significant in the potentialCD group ( $p=0.04$; Figure 3 ). This finding was consistent with the results of duodenal TGF- $\beta 1$ mRNA measurement (See Supplementary Figure 1 in Supplementary Material).

\section{DISCUSSION}

In this case-control study including predominantly young patients, overall $H$. pylori infection rates were similar between subjects with and without CD, and were independent of the severity of duodenal atrophy in the latter. However, in individuals infected by $H$. pylori, detection of cagA + strains was significantly more common among individuals with potential-CD compared to active-CD and non-CD patients. A similar H. pylori prevalence between $\mathrm{CD}$ and non-CD subjects have been previously reported.
Aydogdu et al. found a $22 \%$ of $H$. pylori prevalence in 96 Turkish CD children compared to $24 \%$ in 235 non-CD children (mean age of 8 years old; Aydogdu et al., 2008). Similar prevalence rates were reported by Luzza et al in Italian children with and without CD (Luzza et al., 1999). On the other hand, Simondi et al. determined a higher, but also similar prevalence of $H$. pylori in CD and nonCD adults (36 and $41 \%$, respectively; mean age of 41 years old; Simondi et al., 2015). In contrast to these findings, Lebwohl et al. reported a strong inverse association between the presence of $H$. pylori in gastric mucosa and CD in a large cross-sectional study that included 136,179 patients undergoing upper endoscopy in the USA (OR =0.48; 95\%; CI: 0.40-0.58; Lebwohl et al., 2013). This study was performed in a country with a low-prevalence of H. pylori (prevalence 4.4 and $8.8 \%$ in CD and non-CD subjects, respectively) and included older patients compared to our clinical series (mean age 51 years old vs. 13 years old), which could in part explain the discrepancy.

Milder histological damage among CD patients infected with H. pylori was previously reported by Villanacci et al. (in a group of $80 \mathrm{CD}$ adults $H$. pylori was detected in 7/9 individuals Marsh 1-2 and 23/71 Marsh 3; Villanacci et al., 2006), Aydogdu et al. (in a group of $96 \mathrm{CD}$ children $H$. pylori was detected in $56 \%$ of Marsh 1, 38\% of Marsh 2 and 5\% of Marsh 3, $p<0.05$; Aydogdu et al., 2008), and Simondi et al. (in a group of 73 CD adults $H$. pylori was detected in 50\% of Marsh 1-2 and 33\% of Marsh 3; $p$ $>0.05$; Simondi et al., 2015). Our study differs from the above mentioned because the association between H. pylori and CD related histological damage was the primary and not secondary outcome and we additionally explored the possible effect of a virulence factor (cagA). Overall $H$. pylori prevalence did not differ between potential- and active-CD patients (both nearly 30-40\%); however among infected subjects, the presence of cagA+ strains was significantly associated with milder histological damage (Marsh 0-1). Prevalence of cagA+H. pylori strains vary between populations between 40 and 80\% (Feliciano et al., 2015; O’Ryan et al., 2015; Sayehmiri et al., 2015; Scarpulla et al., 2015) and 
TABLE 4 | Gastric histological findings according to CD and H. pylori (Hp) status.

\begin{tabular}{|c|c|c|c|c|c|c|c|c|c|c|}
\hline & \multicolumn{3}{|c|}{ Potential CD $n=37$} & \multicolumn{3}{|c|}{ Active CD $n=29$} & \multicolumn{3}{|c|}{ Non-CD patients $n=50$} & \multirow[t]{2}{*}{$p$-value } \\
\hline & $\begin{array}{c}H p+\operatorname{cag} A \\
+n=10\end{array}$ & $\begin{array}{c}H p+\operatorname{cag} A \\
-n=1\end{array}$ & $H p-n=26$ & $\begin{array}{c}H p+\operatorname{cag} A \\
+n=4\end{array}$ & $\begin{array}{c}H p+\operatorname{cag} A \\
-n=6\end{array}$ & $H p-n=19$ & $\begin{array}{c}H p+\operatorname{cag} A \\
+n=10\end{array}$ & $\begin{array}{c}H p+\operatorname{cag} A \\
-n=10\end{array}$ & $H p-n=30$ & \\
\hline Normal & 1 & 1 & 13 & 0 & 1 & 9 & 3 & 1 & 19 & n.s. \\
\hline Mild chronic gastritis & 7 & 0 & 11 & 4 & 1 & 9 & 3 & 6 & 10 & n.s. \\
\hline $\begin{array}{l}\text { Moderate chronic } \\
\text { gastritis }\end{array}$ & 2 & 0 & 0 & 0 & 3 & 0 & 4 & 3 & 0 & n.s. \\
\hline Severe chronic gastritis & 0 & 0 & 0 & 0 & 0 & 0 & 0 & 0 & 0 & n.s. \\
\hline Atrophic gastritis & 0 & 0 & 1 & 0 & 0 & 1 & 0 & 0 & 1 & n.s. \\
\hline Intestinal metaplasia & 0 & 0 & 1 & 0 & 1 & 0 & 0 & 0 & 0 & n.s. \\
\hline
\end{tabular}

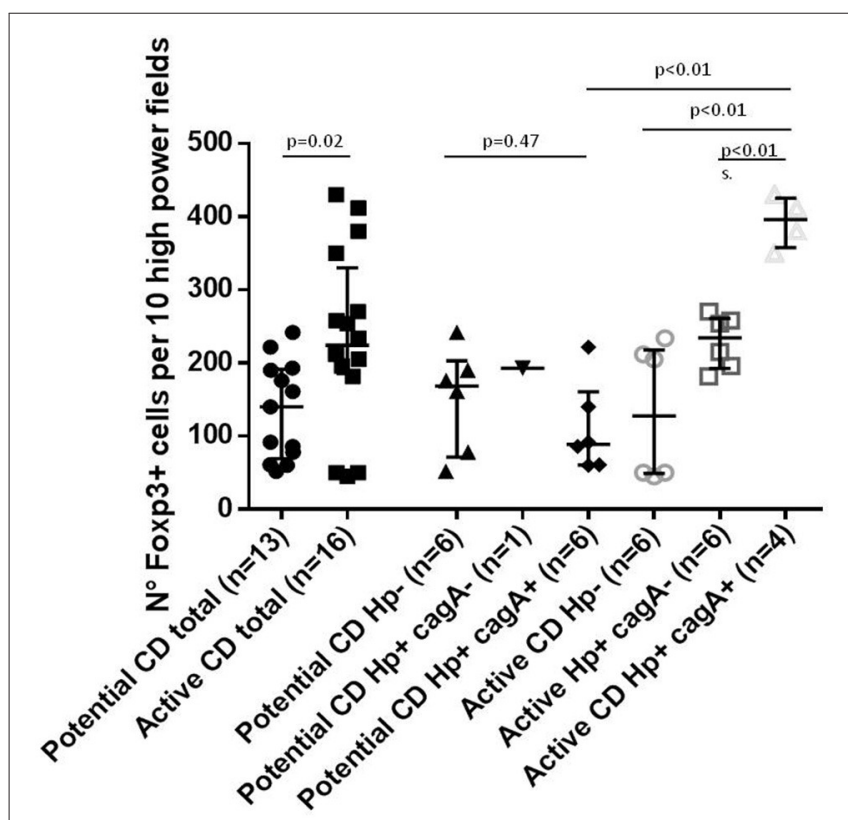

FIGURE 2 | Number of Foxp3 positive cells per 10 high power field in lamina propria stained by immune histochemistry.

could explain at least in part the difference observed between our study and previous findings. The presence/absence of the cag $A+$ gene among infecting $H$. pylori strains is a factor that may be modulating the severity of duodenal lesions. Konturek et al. reported that anti-CagA antibodies were detected significantly less frequently in $H$. pylori+ celiac subjects than in healthy $H$. pylori+ controls (Konturek et al., 2000), which is in line with our findings.

H. pylori infections, which are acquired mostly early in life in Chilean children (O'Ryan et al., 2015), may have a limited role in overall development of $\mathrm{CD}$, possibly modulating disease in subsets of individuals. The fact that for potential-CD subjects infected with $H$. pylori most are infected with $\operatorname{cag} A+$ strains, in contrast to subjects with active disease where most are infected with cagA- strains, suggests that infection with the former pathotype may be modulating disease to less severe forms of presentation.

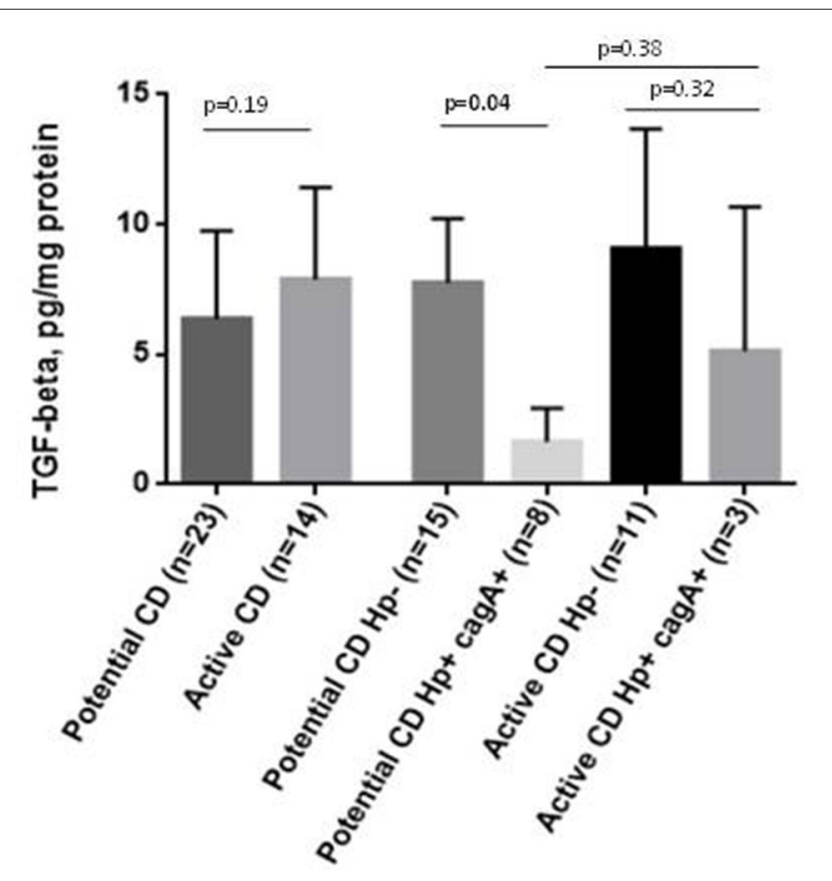

FIGURE 3 | TGF- $\beta 1$ in duodenal mucosa in active CD and potential CD comparing those negative for $H$. pylori and positive for $c a g A+H$. pylori strains in gastric mucosa. TGF- $\beta 1$ levels were quantified by Luminex and expressed per mg of protein.

Conversely, it is possible that gastric/duodenal tissue of these potential-CD individuals is more prone to be colonized with $\operatorname{cag} A+$ strains. However, counter evidence to this hypothesis was reported in a previous Chilean cohort study in which acquisition of persistent $H$. pylori infection occurred mainly during the first 3 years of life (O'Ryan et al., 2015), an age that is 10 years younger than the median age of our series of patients. It is reasonable to extrapolate that in most of our cases, $H$. pylori infection preceded the development of CD. Whether persistently infected children change strains over time, from $\operatorname{cag} A+$ to $\operatorname{cag} A$ - (or vice versa), remains as yet an open question requiring a longitudinal study design.

The number of positive stained Foxp3 cells in duodenal lamina propria and the expression of TGF- $\beta 1$ were higher in 
active than in potential CD patients, consistent with findings by Tiittanen et al. (2008), Brazowski et al. (2010), and Borrelli et al. (2013). In active-CD, the T-reg pathway is fully activated downregulating the ongoing Th1/Th17 inflammatory process (Tiittanen et al., 2008). However, in vitro evidence suggests that effector $\mathrm{T}$ cells become resistant to suppression by T-regs in this setting (Hmida et al., 2012). According to our results, this increase in Foxp3 cells was even more evident in active-CD patients infected with cagA+H. pylori strains. Although duodenal inflammatory profiles have not been previously explored in patients infected with $H$. pylori, this agent has been associated with a local gastric and systemic response characterized by Th1/Th17 inflammatory processes as well as activation of T-reg pathways contributing to infection persistence (Gil et al., 2014; Hussain et al., 2016). The T-reg pathway is especially enhanced in children compared to adults (Freire de Melo et al., 2012; Serrano et al., 2013; Gil et al., 2014) and in individuals infected with cagA $+H$. pylori strains (Kido et al., 2011; Hussain et al., 2016). We hypothesize that priming with cagA $+H$. pylori at a young age, may protect against chronic inflammatory processes and loss of food/self antigen tolerance through activation of the T-reg pathway.

Further studies of cytokine expression in cultured duodenal biopsies of $\mathrm{CD}$ patients exposed in vitro to $H$. pylori with and without cagA gene and cohort studies of high risk CD patients infected and non-infected with $\operatorname{cag} A+H$. pylori strains are needed to confirm this proposal.

Animal models fully reproducing CD are not currently available but comparing potential-CD with active-CD individuals is an interesting "in vivo" model to advance knowledge on mechanisms underlying this condition. The identification of factors that could modulate histological damage and inflammation in $\mathrm{CD}$ can potentially open new avenues for prevention and treatment aiming to improve the quality of life of these patients.

In conclusion, $H$. pylori infection rates were similar among individuals with and without $\mathrm{CD}$, but infection with cagA+ strains was significantly associated with milder histological damage in celiac patients infected by $H$. pylori and in active$\mathrm{CD}$ cases with higher expression of T-reg markers. These results suggest that infection by $\operatorname{cag} A+H$. pylori may be protective for $\mathrm{CD}$ progression, or conversely, that these strains are prone

\section{REFERENCES}

Agardh, D., Lee, H.-S., Kurppa, K., Simell, V., Aronsson, C. A., Jorneus, O., et al. (2015). Clinical features of celiac disease: a prospective birth cohort. Pediatrics 135, 627-634. doi: 10.1542/peds.2014-3675

Araya, M., Oyarzun, A., Lucero, Y., Espinosa, N., and Pérez-Bravo, F. (2015). DQ2, DQ7 and DQ8 distribution and clinical manifestations in celiac cases and their first-degree relatives. Nutrients 7, 4955-4965. doi: 10.3390/nu7064955

Aydogdu, S., Cakir, M., Ali Yuksekkaya, H., Tumgor, G., Baran, M., Arikan, C., et al. (2008). Helicobacter pylori infection in children with celiac disease. Scand. J. Gastroenterol. 43, 1088-1093. doi: 10.1080/00365520802101846

Biagetti, C., Gesuita, R., Gatti, S., and Catassi, C. (2015). Quality of life in children with celiac disease: a paediatric cross-sectional to colonize when intestinal damage is less severe. Future research should focus on clarifying mechanisms involved in this association.

\section{AUTHOR CONTRIBUTIONS}

Substantial contributions to the conception or design of the work: YL, AO, MO, RQ, NE, RV, and MA. Contribution to the acquisition, analysis, or interpretation of data for the work: YL, AO, MO, RQ, NE, RV, DS, EA, CA, MF, AV, IG, JM, JC, GE, MG, JO, EM, FP, MC, and MA. Drafting the work or revising it critically for important intellectual content: $\mathrm{YL}, \mathrm{AO}, \mathrm{MO}, \mathrm{RQ}$, NE, RV, DS, EA, CA, MF, AV, IG, JM, JC, GE, MG, JO, EM, FP, $\mathrm{MC}$, and MA. Final approval of the version to be published: YL, AO, MO, RQ, NE, RV, DS, EA, CA, MF, AV, IG, JM, JC, GE, MG, JO, EM, FP, MC, and MA. Agreement to be accountable for all aspects of the work in ensuring that questions related to the accuracy or integrity of any part of the work are appropriately investigated and resolved: YL, AO, MO, RQ, NE, RV, DS, EA, CA, MF, AV, IG, JM, JC, GE, MG, JO, EM, FP, MC, and MA.

\section{FUNDING}

This study was supported by FONDECYT grant 11121671 .

\section{ACKNOWLEDGMENTS}

We thank our colleagues Dr. Daniel Pizarro, Dr. Carolina Figueroa, Dr. Raúl Acuña, Dr. María Paz Muñoz, Dr. Eduardo Chávez who provided samples and data of patients included in this protocol. We thank Nora Mamani and Ana María Salinas for technical assistance with $H$. pylori PCR.

\section{SUPPLEMENTARY MATERIAL}

The Supplementary Material for this article can be found online at: http://journal.frontiersin.org/article/10.3389/fcimb. 2017.00376/full\#supplementary-material

Supplementary Figure 1 | TGF- $\beta 1$ mRNA relative expression in active CD and potential $\mathrm{CD}$ comparing those negative for $\mathrm{H}$. pylori and positive for cagA+ $\mathrm{H}$. pylori strains in gastric mucosa. $\Delta \mathrm{Ct}$ was calculated by using actin expression as reference and normalized assuming active-CD negative for $\mathrm{H}$. pylori as 1 (samples processed in duplicate). 
Catassi, C., Gatti, S., and Lionetti, E. (2015). World perspective and celiac disease epidemiology. Dig. Dis. 33, 141-146. doi: 10.1159/000369518

Cenit, M., Olivares, M., Codo-er-Franch, P., and Sanz, Y. (2015). Intestinal microbiota and celiac disease: cause, consequence or co-evolution? Nutrients 7, 6900-6923. doi: 10.3390/nu7085314

Collado, M. C., Donat, E., Ribes-Koninckx, C., Calabuig, M., and Sanz, Y. (2009). Specific duodenal and faecal bacterial groups associated with paediatric coeliac disease. J. Clin. Pathol. 62, 264-269. doi: 10.1136/jcp.2008. 061366

Collado, M., Donat, E., Ribes-Koninckx, C., Calabuig, M., and Sanz, Y. (2008). Imbalances in faecal and duodenal Bifidobacterium species composition in active and non-active coeliac disease. BMC Microbiol. 8:232. doi: 10.1186/1471-2180-8-232

Csendes, A., Smok, G., Burdiles, P., Blanco, C., and Rodas, J. (1995). [Presence of Helicobacter pylori in the duodenum, antrum, and fundus in control subjects and patients with duodenal ulcer, gastric ulcer, gastritis, or erosive duodenitis. Histological analysis of 357 subjects]. Rev. Médica Chile 123, 177-184.

Di Cagno, R., De Angelis, M., De Pasquale, I., Ndagijimana, M., Vernocchi, P., Ricciuti, P., et al. (2011). Duodenal and faecal microbiota of celiac children: molecular, phenotype and metabolome characterization. BMC Microbiol. 11:219. doi: 10.1186/1471-2180-11-219

Donaldson, M. R., Book, L. S., Leiferman, K. M., Zone, J. J., and Neuhausen, S. L. (2008). Strongly positive tissue transglutaminase antibodies are associated with Marsh 3 histopathology in adult and pediatric celiac disease. J. Clin. Gastroenterol. 42, 256-260. doi: 10.1097/MCG.0b013e31802e70b1

Feliciano, O., Gutierrez, O., Valdés, L., Fragoso, T., Calderin, A. M., Valdes, A. E., et al. (2015). Prevalence of Helicobacter pylori vacA, cagA, and iceA genotypes in cuban patients with upper gastrointestinal diseases. BioMed. Res. Int. 2015, 1-6. doi: 10.1155/2015/753710

Freire de Melo, F., Rocha, A. M. C., Rocha, G. A., Pedroso, S. H. S. P., de Assis Batista, S., Fonseca de Castro, L. P., et al. (2012). A regulatory instead of an IL-17 T response predominates in Helicobacter pylori-associated gastritis in children. Microbes Infect. 14, 341-347. doi: 10.1016/j.micinf.2011.11.008

Gil, J. H., Seo, J. W., Cho, M.-S., Ahn, J.-H., and Sung, H. Y. (2014). Role of treg and TH17 cells of the gastric mucosa in children with Helicobacter pylori gastritis. J. Pediatr. Gastroenterol. Nutr. 58, 252-258. doi: 10.1097/MPG.0000000000000194

Green, P. H. R., Lebwohl, B., and Greywoode, R. (2015). Celiac disease. J. Allergy Clin. Immunol. 135, 1099-1106. doi: 10.1016/j.jaci.2015.01.044

Harris, P. R., Godoy, A., Arenillas, S., Riera, F., García, D., Einisman, H., et al. (2003). CagA antibodies as a marker of virulence in chilean patients with Helicobacter pylori infection. J. Pediatr. Gastroenterol. Nutr. 37, 596-602. doi: 10.1097/00005176-200311000-00018

Hmida, N. B., Ahmed, M. B., Moussa, A., Rejeb, M. B., Said, Y., Kourda, N., et al. (2012). Impaired control of effector T Cells by regulatory T Cells: a clue to loss of oral tolerance and autoimmunity in celiac disease? Am. J. Gastroenterol. 107, 604-611. doi: 10.1038/ajg.2011.397

Husby, S., Koletzko, S., Korponay-Szabó, I. R., Mearin, M. L., Phillips, A., Shamir, R., et al. (2012). European Society for pediatric gastroenterology, hepatology, and nutrition guidelines for the diagnosis of coeliac disease. J. Pediatr. Gastroenterol. Nutr. 54, 136-160. doi: 10.1097/MPG.0b013e3182 $1 \mathrm{a} 23 \mathrm{~d} 0$

Hussain, K., Letley, D. P., Greenaway, A. B., Kenefeck, R., Winter, J. A., Tomlinson, W., et al. (2016). Helicobacter pylori-Mediated Protection from Allergy Is Associated with IL-10-Secreting Peripheral Blood Regulatory T Cells. Front. Immunol. 7:71. doi: 10.3389/fimmu.2016. 00071

Jozefczuk, J., Bancerz, B., Walkowiak, M., Glapa, A., Nowak, J., Piescikowska, J., et al. (2015). Prevalence of Helicobacter pylori infection in pediatric celiac disease. Eur. Rev. Med. Pharmacol. Sci. 19, 2031-2035.

Kido, M., Watanabe, N., Aoki, N., Iwamoto, S., Nishiura, H., Maruoka, R., et al. (2011). Dual roles of CagA protein in Helicobacter pylori-induced chronic gastritis in mice. Biochem. Biophys. Res. Commun. 412, 266-272. doi: 10.1016/j.bbrc.2011.07.081

Kim, J. W., Kim, J. G., Chae, S. L., Cha, Y. J., and Park, S. M. (2004). High prevalence of multiple strain colonization of Helicobacter pylori in Korean patients: DNA diversity among clinical isolates from the gastric corpus, antrum and duodenum. Korean J. Intern. Med. 19, 1-9. doi: 10.3904/kjim.2004.19.1.1
Konturek, P. C., Karczewska, E., Dieterich, W., Hahn, E. G., and Schuppan, D. (2000). Increased prevalence of Helicobacter pylori infection in patients with celiac disease. Am. J. Gastroenterol. 95, 3682-3683. doi: 10.1111/j.1572-0241.2000.03421.x

Lebwohl, B., Blaser, M. J., Ludvigsson, J. F., Green, P. H. R., Rundle, A., Sonnenberg, A., et al. (2013). Decreased risk of celiac disease in patients with Helicobacter pylori colonization. Am. J. Epidemiol. 178, 1721-1730. doi: 10.1093/aje/kwt234

Lionetti, E. (2014). Helicobacter pylori infection and atopic diseases: is there a relationship? A systematic review and meta-analysis. World J. Gastroenterol. 20:17635. doi: 10.3748/wjg.v20.i46.17635

Lundgren, A., Strömberg, E., Sjöling, A., Lindholm, C., Enarsson, K., Edebo, A., et al. (2005). Mucosal FOXP3-expressing CD4+ CD25high regulatory $\mathrm{T}$ cells in Helicobacter pylori-infected patients. Infect. Immun. 73, 523-531. doi: 10.1128/IAI.73.1.523-531.2005

Luzza, F., Mancuso, M., Imeneo, M., Mesuraca, L., Contaldo, A., Giancotti, L., et al. (1999). Helicobacter pylori infection in children with celiac disease: prevalence and clinicopathologic features. J. Pediatr. Gastroenterol. Nutr. 28, 143-146. doi: 10.1097/00005176-199902000-00009

Marsh, M. N. (1989). The immunopathology of the small intestinal reaction in gluten-sensitivity. Immunol. Invest. 18, 509-531. doi: $10.3109 / 08820138909112260$

Minsal Chile (2010). Encuesta Nacional de Salud Chile 2009-2010. 1-1064.

Nagasawa, S., Azuma, T., Motani, H., Sato, Y., Hayakawa, M., Yajima, D., et al. (2009). Detection of Helicobacter pylori (H.pylori) DNA in digestive systems from cadavers by real-time PCR. Leg. Med. 11, S458-S459. doi: 10.1016/j.legalmed.2009.03.001

O’Ryan, M. L., Lucero, Y., Rabello, M., Mamani, N., Salinas, A. M., Pe-a, A., et al. (2015). Persistent and Transient Helicobacter pylori infections in early childhood. Clin. Infect. Dis. 61, 211-218. doi: 10.1093/cid/civ256

Porras, C., Nodora, J., Sexton, R., Ferreccio, C., Jimenez, S., Dominguez, R. L., et al. (2013). Epidemiology of Helicobacter pylori infection in six Latin American countries (SWOG Trial S0701). Cancer Causes Control CCC 24, 209-215. doi: $10.1007 / \mathrm{s} 10552-012-0117-5$

Sayehmiri, F., Kiani, F., Sayehmiri, K., Soroush, S., Asadollahi, K., Alikhani, M. Y., et al. (2015). Prevalence of cagA and vacA among Helicobacter pylori-infected patients in Iran: a systematic review and meta-analysis. J. Infect. Dev. Ctries. 9, 686-696. doi: 10.3855/jidc.5970

Scarpulla, G., Giammanco, A., Di Carlo, E., Calà, C., Camilleri, S., Bonura, C., et al. (2015). Resistance to clarithromycin and genotypes in Helicobacter pylori strains isolated in Sicily. J. Med. Microbiol. 64, 1408-1414. doi: 10.1099/jmm.0.000163

Schøsler, L., Christensen, L. A., and Hvas, C. L. (2016). Symptoms and findings in adult-onset celiac disease in a historical Danish patient cohort. Scand. J. Gastroenterol. 51, 288-294. doi: 10.3109/00365521.2015.1092576

Sepúlveda, E., Moreno, J., Spencer, M. L., Quilodrán, S., Brethauer, U., Brice-o, C., et al. (2012). Comparación de Helicobacter pylori en cavidad oral y mucosa gástrica de acuerdo a genotipo de virulencia (cagA y vacAm 1). Rev. Chil. Infectol. 29, 278-283. doi: 10.4067/S0716-10182012000300005

Serrano, C., Wright, S. W., Bimczok, D., Shaffer, C. L., Cover, T. L., Venegas, A., et al. (2013). Downregulated Th17 responses are associated with reduced gastritis in Helicobacter pylori-infected children. Mucosal Immunol. 6, 950-959. doi: 10.1038/mi.2012.133

Simondi, D., Ribaldone, D. G., Bonagura, G. A., Foi, S., Sapone, N., Garavagno, M., et al. (2015). Helicobacter pylori in celiac disease and in duodenal intraepithelial lymphocytosis: active protagonist or innocent bystander? Clin. Res. Hepatol. Gastroenterol. 39, 740-745. doi: 10.1016/j.clinre.2015. 03.005

Stein, M., Ruggiero, P., Rappuoli, R., and Bagnoli, F. (2013). Helicobacter pylori CagA: from pathogenic mechanisms to its use as an anti-cancer vaccine. Front. Immunol. 4:328. doi: 10.3389/fimmu.2013.00328

Stolte, M., and Meining, A. (2001). The updated sydney system: classification and grading of gastritis as the basis of diagnosis and treatment. Can. J. Gastroenterol. 15, 591-598. doi: 10.1155/2001/367832

Taye, B., Enquselassie, F., Tsegaye, A., Medhin, G., Davey, G., and Venn, A. (2015). Is Helicobacter Pylori infection inversely associated with atopy? A systematic review and meta-analysis. Clin. Exp. Allergy 45, 882-890. doi: $10.1111 /$ cea. 12404 
Tiittanen, M., Westerholm-Ormio, M., Verkasalo, M., Savilahti, E., and Vaarala, O. (2008). Infiltration of forkhead box P3-expressing cells in small intestinal mucosa in coeliac disease but not in type 1 diabetes: FoxP3 expression in gut in coeliac disease. Clin. Exp. Immunol. 152, 498-507. doi: 10.1111/j.1365-2249.2008.03662.x

Villanacci, V., Bassotti, G., Liserre, B., Lanzini, A., Lanzarotto, F., and Genta, R. M. (2006). Helicobacter pylori infection in patients with celiac disease. Am. J. Gastroenterol. 101, 1880-1885. doi: 10.1111/j.1572-0241.2006.00621.x

Yang, Y.-J., Chuang, C.-C., Yang, H.-B., Lu, C.-C., and Sheu, B.-S. (2014). Susceptibility to pediatric Helicobacter pylori infection correlates with the host responses of regulatory and effector T Cells: pediatr. Infect. Dis. J. 33, 1277-1282. doi: 10.1097/INF.0000000000000464
Conflict of Interest Statement: The authors declare that the research was conducted in the absence of any commercial or financial relationships that could be construed as a potential conflict of interest.

Copyright (C) 2017 Lucero, Oyarzún, O'Ryan, Quera, Espinosa, Valenzuela, Simian, Alcalde, Arce, Farfán, Vergara, Gajardo, Mendez, Carrasco, Errázuriz, Gonzalez, Ossa, Maiza, Perez-Bravo, Castro and Araya. This is an open-access article distributed under the terms of the Creative Commons Attribution License (CC BY). The use, distribution or reproduction in other forums is permitted, provided the original author(s) or licensor are credited and that the original publication in this journal is cited, in accordance with accepted academic practice. No use, distribution or reproduction is permitted which does not comply with these terms. 